\title{
INVESTIGATION ON TENSILE STRENGTH OF CELLULOSE MICROFIBRIL REINFORCED POLYMER COMPOSITES
}

\author{
VIGNESH PRAGASAM and DEGALAHAL MALLIKARJUNA REDDY \\ School of Mechanical Engineering, Vellore Institute of Technology, \\ Vellore, 632014, Tamil Nadu, India \\ ¿ Corresponding author: D. Mallikarjuna Reddy,dmreddy@vit.ac.in
}

Received October 10, 2019

\begin{abstract}
This research work aims to find the tensile stress and the tensile modulus of cellulose microfibril (CMF) reinforced epoxy polymer composites. CMFs were extracted from banana fibers using the acid-alkali treatment. Scanning electron microscopy (SEM) images revealed the isolation of $\alpha$-cellulose of $1-2 \mu \mathrm{m}$ after the acid-alkali treatment. Thermogravimetric analysis showed an increase in the thermal resistance of CMFs up to $380^{\circ} \mathrm{C}$, compared to $260{ }^{\circ} \mathrm{C}$ for untreated natural fiber. The influence of three parameters, namely $\mathrm{NaOH} \%(\mathrm{w} / \mathrm{w})$, fiber diameter $(\mu \mathrm{m})$ and fiber volume $\%(\mathrm{w} / \mathrm{w})$, on the tensile behavior of composites was investigated. Response surface methodology (RSM), a DOE tool, was used for determining the composition of different specimens. A three-factor, three-level Box-Behnken Design (BBD) model of RSM was selected for investigating the effect of input variables on the tensile behaviors and to obtain the optimization conditions. By solving the regression equations and analyzing the 3D response surface plots obtained from $\mathrm{BBD}$, the optimized desirability ramp values were obtained. The optimized tensile stress and tensile modulus values were $41.78 \mathrm{MPa}$ and $10380 \mathrm{MPa}$, respectively, using optimized values of $\mathrm{NaOH} \%$ (w/w), fiber diameter $(\mu \mathrm{m})$ and fiber volume\% $(\mathrm{w} / \mathrm{w})$ of $18.32,250$ and 4.05 respectively.
\end{abstract}

Keywords: Box-Behnken Design, response surface methodology, optimization approach, microfibrils, epoxy composites, tensile strength

\section{INTRODUCTION}

Natural fiber-reinforced composites are in the research focus with a view of replacing synthetic composites for many reasons. Natural fiberreinforced composites can possibly diminish the carbon print and environmental pollution, while improving the biodegradability of composites. Nowadays, natural fiber-reinforced composites find many applications and can replace synthetic composites in most structural and non-structural applications. Natural fibers are used in different ways for fabricating composites: as woven mats, or non-woven, short, micro- and nano-sized fibers. ${ }^{1}$ Cellulose is the primary element in natural fiber that provides it with adequate strength to withstand huge loads. Cellulose microfibrils and cellulose nanofibrils have gained much attention in structural composites applications. ${ }^{2}$ Chemical treatments are applied to natural fibers for achieving better interaction with the polymer matrix and to improve the mechanical properties of natural fiber-reinforced composites. ${ }^{3}$ Edeerozey et al. chemically treated kenaf fiber with a $\mathrm{NaOH}$ solution for attaining better interaction with the matrix. Also, chemical treatment cleans the surface of the fiber, limits moisture absorption, and increases the surface roughness of the fiber. It was observed that the chemical treatment enhances the mechanical properties, compared to those of untreated fibers. ${ }^{4}$

Feng et al. studied the effect of using a compatibilizer with kenaf fiber and the structural changes induced when treated kenaf fiber was added as reinforcement of polypropylene. Maleated polypropylene (MAPP) was used to improve the adhesion between kenaf fiber and the polypropylene matrix. This coupling agent improved the bonding strength and enhanced the crystallization temperature of polymer composites. ${ }^{5}$ Kalia et al. reviewed different chemical treatments applied to natural fibers, their application in real-world conditions when they are used as reinforcement in polymer composites. Chemical treatments modify the surface of natural fibers and provide better adhesive interaction with 
the polymer achieving higher load-carrying abilities, as compared with those of untreated natural fiber composites. ${ }^{6}$ Rokbi et al. investigated the effect of chemical treatment of natural fiber-reinforced composites on their flexural strength. Alfa fiber, extracted from Stipa tenacissima, was alkali treated with different alkali doses, and the flexural properties of natural fiber-reinforced composites were studied. The results showed that alkali treatment altered the hydrophilic characteristic of natural fiber and improved the adhesion between the matrix and the fiber. This increased the mechanical and thermal properties of chemically treated natural fiberreinforced composites. ${ }^{7}$ Kabir et al. compared the effect of different surface treatments on natural fibers for advanced composite applications. Some surface treatments, such as alkali, permanganate, isocyanide, peroxide and saline, improved mechanical strength and dimensional stability, compared with those of pristine samples. ${ }^{8}$

Joseph et al. investigated the thermal properties of sisal short fiber reinforced polypropylene (PP) matrix composites. Sisal fibers were chopped, treated with a $\mathrm{KMnO}_{4}$ solution and then used to reinforce PP to make composites. TGA results of the treated fiber composites showed improved thermal properties, as compared to those of untreated fiber composites. ${ }^{9}$ Zhou et al. studied the interface and bonding mechanism of chemically treated and untreated fibers with a polymer matrix. The mechanical properties of natural fiber-reinforced composites were improved by optimizing the interaction of plant fiber with the polymer matrix. The authors suggested some guidelines to improve the interaction of natural fiber with the polymer matrix. ${ }^{10}$ Sepe et al. investigated the mechanical properties of chemically treated hemp fiber-reinforced composites. Glycidyloxypropyl) trimethoxysilane acts as a coupling agent and, along with alkaline treatment, improves the mechanical properties of hemp fiber-reinforced composites. ${ }^{11}$ Rashed et al. studied the tensile strength of jute fiber-reinforced composites. The effects of parameters, such as alkali treatment (compared to no treatment), fiber size (1, 2 and $4 \mathrm{~mm}$ ) and fiber loading (5, 10, 15 wt $\%$ ) were considered. They analyzed the tensile behavior and performed fractographic observations. $^{12-13}$

Ochi examined the mechanical properties of kenaf fiber-reinforced composites. The author investigated the effect of thermal treatment on the tensile properties of kenaf fiber. The biodegradability of kenaf/PLA composites was also analyzed. ${ }^{14}$ Additionally, kenaf fibers were treated with an alkaline solution before being used as reinforcement in epoxy composites. A thermal degradation test was carried out and the results showed improved thermal stability of the treated kenaf fiber composites, compared to untreated kenaf fiber ones. ${ }^{15}$ Malkapuram et al. reviewed some recent developments in polypropylene based composites reinforced with various natural fibers. In general, abundantly available natural fibers, such as jute, coir, banana hemp and flax fibers, are used as reinforcement. Banana fibers, treated with $10 \% \mathrm{NaOH}$ solution, have been demonstrated to improve the thermo-physical properties of composites, compared with untreated fibers. ${ }^{16-17}$

Harish et al. evaluated the mechanical properties of coir fiber-reinforced composites. Coir fiber was cut into short pieces and then used to reinforce an epoxy matrix. The tensile testing results showed coir fiber as a suitable reinforcement for low load-bearing applications. ${ }^{18}$ Haque et al. investigated the physical-mechanical properties of polypropylene composites reinforced with chemically treated palm and coir fibers. The fibers were added at five loading levels, from 15 to $35 \mathrm{wt} \%$, relative to the matrix, and mechanical tests, such as tensile, flexural and impact analyses, were carried out. The results proved that the $30 \mathrm{wt} \%$ fiber loaded sample showed better mechanical properties. ${ }^{19}$ Lee et al. fabricated polypropylene composites reinforced with long and discontinuous natural fibers and investigated their mechanical properties. $^{20}$ Ornaghi et al. explored the hybridization effect of curaua and glass fibers on the mechanical and dynamic properties of composites. They found that an increase in the weight percentage of curaua had a minimum effect, compared to that of glass fiber. ${ }^{21}$ Akil et al. reviewed kenaf fiberreinforced composites. Kenaf fibers are readily available and are used as reinforcement in various ways. $\mathrm{NaOH}$ treated kenaf fiber increases the tensile and flexural properties of epoxy composites, but the thermal resistance decreased, compared to that of untreated kenaf fiberreinforced composites. ${ }^{22}$ Prasad et al. investigated jowar, sisal and bamboo reinforced composites under mechanical testing. The fibers were reinforced at $40 \%$ vol. ratio and tested them in terms of tensile and flexural strengths. ${ }^{23}$ Sathishkumar et al. investigated the tensile and 
flexural behaviors of snake grass fiber-reinforced composites. Untreated chopped snake grass fibers were added to isophthalic polyester resin and it turned out that an increase in the volumetric fraction increases the tensile and flexural properties of composites. ${ }^{24}$ Venkateshwaran et al. investigated the tensile properties of hybrid natural fiber reinforced composites. They used banana/sisal in different ratios by maintaining a $40 \%$ vol. ratio with the matrix, and compared the experimental tensile strength with that predicted by the rule of hybrid mixture (RoHM). ${ }^{25}$ Ramesh et al. evaluated the mechanical properties of sisaljute-glass fiber reinforced composites. The composites were tested in terms of tensile, flexural and impact strengths, as well as interfacial properties. They analyzed the internal structure of composites using a scanning electron microscope (SEM). ${ }^{26}$

Jawaid et al. studied the effect of jute fiber and oil palm fiber reinforced epoxy composites. The composites were tested in terms of their damping and tensile properties and were found suitable for applications in the automobile and building industries. ${ }^{27}$ Sanjay et al. studied the mechanical properties of banana/glass fiber reinforced composites. They conducted tensile, flexural, impact and hardness tests on the composites. They also investigated the water absorption tendency for pure glass fiber composites and pure banana fiber composites. ${ }^{28}$ Gunti et al. investigated the mechanical and degradation properties of jute, sisal and elephant grass reinforced composites. The fibers were treated by mercerization and bleaching processes. They added treated and untreated fibers to polylactic acid (PLA), in different weight ratios, through the injection process, and compared the mechanical properties, water absorption ability, thermal degradation, soil burial degradation and enzymatic degradation of the composite combinations. Their results showed that chemical treatment increases the flexural property of the composites and decreases their thermal degradation. ${ }^{29} \mathrm{Wu}$ et al. fabricated kenaf fiberreinforced composites and tested them in terms of mechanical properties. They additionally investigated the energy consumption and environmental impact of kenaf fiber composites and compared them with glass fiber composites. They suggested possible replacement of the automotive glass-fiber sheets with natural fiber reinforced composite sheets. ${ }^{30}$ Baley et al. investigated the compressive and tensile behaviors of flax and jute fiber reinforced composites. The fibers were treated with a coupling agent, reinforced with matrix, tested under compressive and tensile conditions, and were found suitable for application in low weight structures. ${ }^{31}$ Sanjay et al. reviewed different characteristics and properties of natural fiber reinforced composites. Natural fiber reinforced composites were discussed with regard to their tensile, flexural, impact, inter-laminar, thermal and hardness behaviors and compared with synthetic fiber reinforced composites. Also, their water absorption capabilities, thermal and tribological properties were considered. The results showed that chemical treatment increases the thermal resistance of the fiber used for reinforcement of the polymer. The fiber matrix adhesion and inter-laminar delamination properties were also analyzed. ${ }^{32}$

Alaaeddin et al. investigated the physical and mechanical properties of sugarcane fiber reinforced composites. Short sugarcane fiber was added to polyvinylidene fluoride using the injection molding process and then the mechanical and physical properties of the composites were analyzed. ${ }^{33-34}$ Navaneethakrishnan et al. analyzed the structural properties of natural fiber reinforced composites. They attempted to reinforce polymer matrix with sisal and luffa fibers by the compression molding process. They conducted tensile, impact and flexural experiments. ${ }^{35}$ Cavalcanti et al. performed the mechanical characterization of intra-laminar natural fiber reinforced composites. They used alkaline treated and untreated jute, sisal and curaua fibers as reinforcement for composites. They investigated the effect of alkaline treatment of the fibers on the mechanical properties of the composites by tensile and flexural tests. ${ }^{36}$ Adeniyi et al. reviewed coir fiber reinforced composites and their applications. Coir fiber is abundantly available as a waste byproduct and hence it can be used with different resin matrices for different applications. Coir fibers were treated with an acid-alkaline solution to increase the $\alpha$-cellulose content and thus the thermal stability and mechanical properties of fiber increased. When treated coir fibers were used as reinforcement of an epoxy matrix, the results showed improved mechanical properties, compared to untreated coir fibers. Coir fiber has good cellulose content and so it can be used for structural applications. ${ }^{37}$ Senthilkumar et al. evaluated the mechanical and vibration properties 
of pineapple leaf fiber (PALF) reinforced composites. They prepared the PALF polyester composites by the hand lay-up process and then compressed the materials using a compression testing machine. They analyzed the tensile, flexural and vibration results and found that an increase in PALF reinforcement increases the mechanical strength and reduces the damping ratio of the composites. They suggested that 45 wt $\%$ PALF composites are better suited for structural applications. ${ }^{38}$ Along with structural applications, cellulose microfibril reinforced composites were used for making thin films, bags and other packaging applications. ${ }^{39}$

From the literature survey, it can be concluded that limited attempts have been made by researchers regarding the optimization of chemical treatment and fiber size to improve the mechanical properties of natural cellulose microfibril reinforced composites. Response surface methodology (RSM) is a powerful statistical-based technique for modeling complex systems, evaluating the simultaneous effects of several factors and obtaining optimum conditions for a desirable response using Derringer's design function methodology. ${ }^{40-41}$ Also, other authors have applied the Box-Behnken Design (BBD) for modeling the optimum tensile and flexural properties of composites. ${ }^{42-43}$

Hence, in this study, the Box-Behnken response surface design (BBD) was used to investigate the tensile strength of cellulose microfibril reinforced composites and to obtain the optimized desirable values of the parameters of interest. The influence of key independent variables, such as $\mathrm{NaOH} \%(\mathrm{w} / \mathrm{w})$, fiber diameter $(\mu \mathrm{m})$ and fiber volume\% $(\mathrm{w} / \mathrm{w})$, on the tensile stress and tensile modulus (dependent variables) of the developed composites were investigated.

\section{EXPERIMENTAL Raw materials}

Raw banana stem fibers were purchased from local suppliers (ECO Green unit, Coimbatore, TN, India) and ground to micron size to be used as filler. The chemicals used for the extraction of cellulose microfibrils: $\mathrm{NaOH}, \mathrm{HCl}$ and demineralized water, were purchased from SRL chemicals, Sigma Aldrich and NICE Chemicals. Epoxy LY556 and hardener HY951 were purchased from S.M. Composites, Chennai, TN, India.

\section{Chemical treatment of fibers}

Raw banana fibers were cut to 4-5 mm length and prewashed with demineralized water to remove dirt and impurities. Then, the fibers were air-dried for two days to remove excess moisture. Fully dried banana fibers were powdered by the pulverizing process (Saral Pulverizer, Gujarat, India) and size separation was performed using a sieve shaker. Figure 1 describes the procedure for the chemical treatment of powdered banana fiber to prepare cellulose microfibrils for reinforcement of epoxy composites.

The chopped banana fibers were pretreated with different w/w percentages of a sodium hydroxide $(\mathrm{NaOH})$ solution for 2 hours, as shown in Table 1 . Then, the fibers were washed several times with distilled water. The pretreated banana fibers were hydrolyzed using a $1 \mathrm{M} \mathrm{HCl}$ solution at $80{ }^{\circ} \mathrm{C} \pm 5{ }^{\circ} \mathrm{C}$ for 2 hours. Then, the fibers were washed several times with demineralized water.

The acid hydrolyzed fibers were treated again with a $2 \%(w / w) ~ N a O H$ solution for 2 hours at $60{ }^{\circ} \mathrm{C} \pm 5$ ${ }^{\circ} \mathrm{C}$. The acid-alkali treated fibers were washed several times with demineralized water until the $\mathrm{pH}$ reached 7. These acid-alkali treated fibers had higher content of cellulose microfibrils and less pectin, hemicelluloses and lignin.

\section{Morphology of microfibrils}

The surface morphology of untreated and chemically treated cellulose microfibrils was examined using a ZEISS EVO18 Scanning Electron Microscope (ZEISS Microscopy, NY, USA). The microscope was operated at $10 \mathrm{kV}$ to observe the microfibrils. The microfibrils were placed on metal stubs by using double-faced tape and the surface was coated by gold using a QUORUM Sputter Coater.

\section{Thermogravimetric analysis (TGA)}

Thermogravimetric analysis is used to perform the thermal degradability of untreated and treated microfibrils. The samples of $200 \mathrm{mg}$ were placed in a platinum pan of SDT Q600 (TA Instruments, USA) and their thermal behavior was analyzed from ambient temperature to $800{ }^{\circ} \mathrm{C}$, at a heating rate of $10{ }^{\circ} \mathrm{C} / \mathrm{min}$, in a nitrogen environment at a flow rate of $25 \mathrm{~mL} / \mathrm{min}$.

\section{Experimental design}

A three-level three-factor Box-Behnken Design (BBD), requiring 15 experiments, was employed in this study. The fractional factorial design, consisting of 3 factors, has to be placed with equally spaced values as $-1,0,+1$. The variables and their levels selected for this study were as follows: $\mathrm{NaOH}(15,17.5$ and 20 in $\% \mathrm{w} / \mathrm{w})$, fiber diameter $(250,375$ and $500 \mu \mathrm{m})$ and fiber volume (2, 4 and 6 in $\% \mathrm{w} / \mathrm{w})$, as shown in Table 1. The data obtained were fitted to a second-order polynomial model, as shown in the next equation: ${ }^{41}$ $Y=\beta_{0}+\sum_{i=1}^{k} \beta_{i} X_{i}+\sum_{i=1}^{k} \beta_{i 1} X_{i}^{2}+\sum_{i=1}^{k} \Sigma_{j=1}^{k} \beta_{i j} X_{i} X_{j}+\varepsilon$ where $\mathrm{Y}$ is the response (tensile stress and tensile modulus); $\beta_{0}, \beta_{\mathrm{i}}(\mathrm{i}=1,2,3,4)$ and $\beta_{\mathrm{ij}}(\mathrm{i}=1,2,3,4 ; \mathrm{j}=$ $1,2,3,4)$ are the model coefficients, and $X_{i}$ and $X_{j}$ are the coded independent variables. BBD was applied to 
the experimental data using the Design Expert statistical software, version 11.

\section{Preparation of samples}

Table 2 shows the order of the experiment to be followed to prepare the samples according to BBD. Tensile test samples were prepared according to ASTM D3039/D3039-17. ${ }^{44}$ The dimensions of the tensile samples were $250 \mathrm{~mm} \times 25 \mathrm{~mm} \times 2.5 \mathrm{~mm}$.

The cellulose microfibrils were prepared according to Table 2, mixed with epoxy resin and stirred mechanically for 45 minutes to obtain their uniform dispersion in the epoxy. Then, $10 \% \mathrm{v} / \mathrm{v}$ hardener was added to the epoxy/filler mixture and stirred for 10 minutes. The mixture was transferred to a tensile testing mold for curing. The samples were cured for 4 hours and the samples were left undisturbed for 1 day for complete curing. For each combination, triplicate samples were prepared for testing. 45 specimens were prepared based on the BBD model. Also, triplicate pure epoxy samples of the same dimension were prepared for comparison purposes.

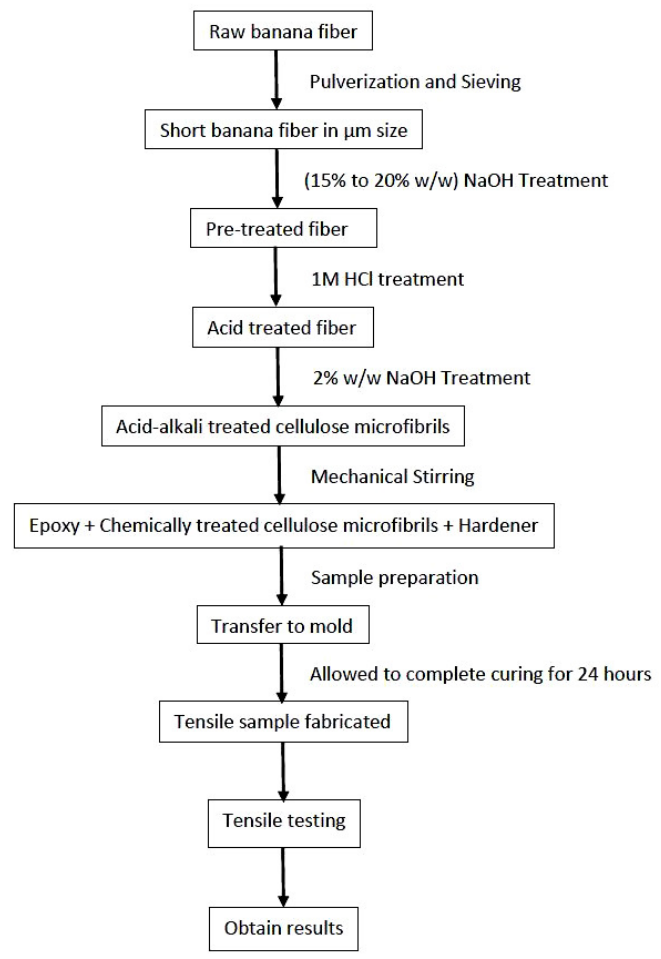

Figure 1: Process flowchart for tensile sample preparation

\section{Tensile testing method}

The specimens were tested using a computerized INSTRON 8801 machine (INSTRON, Norwood, MA, US) by clamping both specimen ends using grippers and axial load was applied gradually. The strain rate of $1 \mathrm{~mm} / \mathrm{min}$ was maintained at room temperature (25 $\left.{ }^{\circ} \mathrm{C}\right)$. During testing, the machine recorded all the values automatically.

\section{Data analysis}

The experimental data obtained by testing were analyzed using the Design Expert analytical software, version 11

Table 1

Levels and codes chosen for Box-Behnken Design

\begin{tabular}{clccc}
\hline \multirow{2}{*}{ Factor } & \multicolumn{2}{c}{ Variables } & \multicolumn{3}{c}{ Coded levels of variables } \\
\cline { 3 - 5 } & & -1 & 0 & +1 \\
\hline $\mathrm{X}_{1}$ & $\mathrm{NaOH} \%(\mathrm{w} / \mathrm{w})$ & 15 & 17.5 & 20 \\
$\mathrm{X}_{2}$ & Fiber diameter $(\mu \mathrm{m})$ & 250 & 375 & 500 \\
$\mathrm{X}_{3}$ & Fiber volume\% $(\mathrm{w} / \mathrm{w})$ & 2 & 4 & 6 \\
\hline
\end{tabular}


Table 2

Box-Behnken Design with actual/coded values for three size fractions

\begin{tabular}{cccc}
\hline Run no. & $\mathrm{NaOH} \%(\mathrm{w} / \mathrm{w})$ & Fiber diameter $(\mu \mathrm{m})$ & Fiber volume\% $(\mathrm{w} / \mathrm{w})$ \\
\hline 1 & $20(+1)$ & $375(0)$ & $6(+1)$ \\
2 & $15(-1)$ & $375(0)$ & $2(-1)$ \\
3 & $17.5(0)$ & $375(0)$ & $4(0)$ \\
4 & $15(-1)$ & $250(-1)$ & $4(0)$ \\
5 & $20(+1)$ & $500(+1)$ & $4(0)$ \\
6 & $17.5(0)$ & $500(+1)$ & $2(-1)$ \\
7 & $17.5(0)$ & $500(+1)$ & $6(+1)$ \\
8 & $17.5(0)$ & $375(0)$ & $4(0)$ \\
9 & $17.5(0)$ & $250(-1)$ & $2(-1)$ \\
10 & $17.5(0)$ & $250(-1)$ & $6(+1)$ \\
11 & $15(-1)$ & $375(0)$ & $6(+1)$ \\
12 & $20(+1)$ & $375(0)$ & $2(-1)$ \\
13 & $17.5(0)$ & $375(0)$ & $4(0)$ \\
14 & $20(+1)$ & $250(-1)$ & $4(0)$ \\
15 & $15(-1)$ & $500(+1)$ & $4(0)$ \\
Pure epoxy $(16)$ & 0 & 0 & 0 \\
\hline
\end{tabular}

The main methodology involved getting tensile results (i.e. tensile stress and tensile modulus were fed), performing the analysis of variance (ANOVA), generating the regression equation through regression analysis and plotting 3D contour plots between dependent and independent variables to establish optimum conditions for tensile stress and tensile modulus.

\section{RESULTS AND DISCUSSION Morphology of microfibrils}

Figure 2 (a) shows the SEM micrograph of untreated fiber. In the raw fiber, $\alpha$-cellulose, hemicelluloses and lignin are bonded to each other forming a compound structure. $\alpha$-Cellulose has high Young's modulus, compared to other elements. Hence, chemical treatment is carried out to extract the $\alpha$-cellulose from the raw fiber. Figure 2 (b) shows the SEM image of banana fiber treated with $17.5 \%$ (w/w) $\mathrm{NaOH}, 1 \mathrm{M} \mathrm{HCl}$ solution and $2 \%(\mathrm{w} / \mathrm{w}) \mathrm{NaOH}$ solution. Figure 3 shows the cellulose microfibrils of $2.43 \mu \mathrm{m}$ in diameter and $19.54 \mu \mathrm{m}$ length. ${ }^{45}$ The pretreatment helped increase the surface area of fibers, exposing the polysaccharides to acidic medium. Acid treatment hydrolyzes the polysaccharides into simple sugars and solubilizes hemicelluloses. Alkali treatment dilutes the remaining pectin, lignin and hemicellulose. ${ }^{2}$ Untreated banana fibers have primary cell walls, wax, dust and other foreign particles. These unwanted contents do not bond with the matrix and hence reduce the mechanical strength of the composites. During chemical treatment, these unwanted materials are removed one by one and $\alpha$-cellulose is exposed to the matrix, leading to good bonding in composites. This increases the mechanical strength of cellulose microfibril reinforced composites, compared to that of untreated banana fiber reinforced composites. ${ }^{46}$

\section{Thermostability analysis of microfibrils}

Cellulose microfibrils are considered to be a promising candidate for reinforcement of polymer materials. Most commercially used polymers can withstand temperatures over $250{ }^{\circ} \mathrm{C}$. Thus, cellulose microfibrils must withstand this operating temperature as well to be suitable for such application. Thermogravimetric analysis was used to study the thermal stability of cellulose microfibrils. ${ }^{9}$

Figure 3 shows the thermogravimetric curves for untreated banana fiber and chemically modified cellulose microfibrils treated with $17.5 \%(\mathrm{w} / \mathrm{w}) \mathrm{NaOH}, 1 \mathrm{M} \mathrm{HCl}$ solution and $2 \%$ $(w / w) \mathrm{NaOH}$ solution. It can be noted from the curves that, from $200{ }^{\circ} \mathrm{C}$ to $300{ }^{\circ} \mathrm{C}$, the raw untreated fiber lost almost $40 \%$ of its weight, whereas the acid-alkali treated cellulose microfibrils lost only about $10 \%$. This indicates an improvement in the thermal stability of the acid-alkali treated cellulose microfibrils, which was 3 times higher than that of the untreated fiber. ${ }^{32-34}$ From $300{ }^{\circ} \mathrm{C}$ to $400{ }^{\circ} \mathrm{C}$, the acid-alkali treated cellulose microfibrils entered a slow and steady weight loss phase, whereas untreated fibers lost weight rapidly. It is evident that the chemically treated fibers have higher thermal resistance, making them suitable for reinforcing 
composites. Untreated fibers contain more soluble sugars, compared to chemically treated cellulose microfibrils. These soluble sugars degrade early in the decomposition process. Hence, untreated banana fibers started decomposing at a temperature of around $230{ }^{\circ} \mathrm{C}$, while chemically treated CMFs could withstand up to $360{ }^{\circ} \mathrm{C}$, without significant weight loss. ${ }^{47-48}$ Both samples were analyzed up to $800{ }^{\circ} \mathrm{C}$ and their residues ranged from $19 \%$ to $22 \%$.
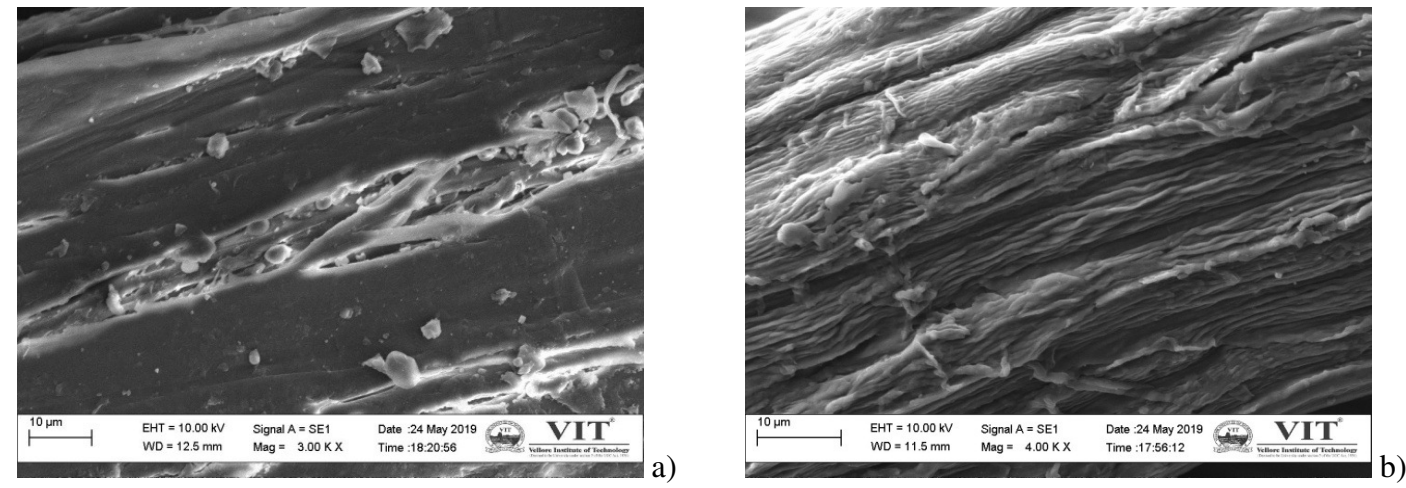

Figure 2: SEM images of a) untreated banana fibers, b) $17.5 \%$ (w/w) $\mathrm{NaOH}, 1 \mathrm{M} \mathrm{HCl}, 2 \%$ (w/w) $\mathrm{NaOH}$ treated cellulose microfibrils

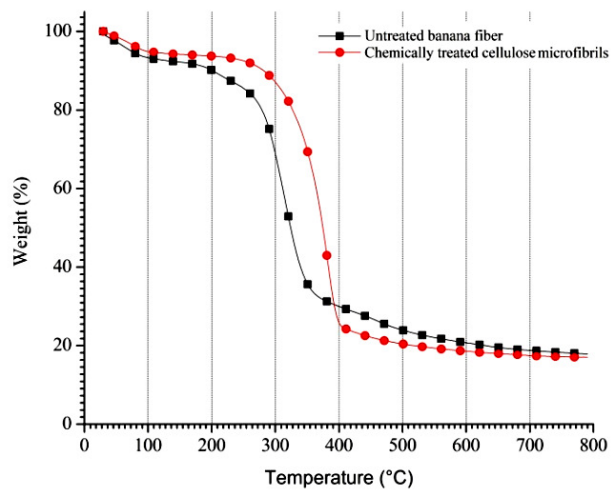

Figure 3: TGA curves of untreated banana fiber and $17.5 \%$ (w/w) $\mathrm{NaOH}, 1 \mathrm{M} \mathrm{HCl}, 2 \%$ (w/w) $\mathrm{NaOH}$ treated cellulose microfibrils

\section{Tensile test analysis}

Tensile specimens prepared according to ASTM standards are shown in Figure 4. The tensile sample was fixed between the top and bottom grippers of the INSTRON machine, ensuring no slip occurred during testing. During testing, an axial load was applied gradually on the specimen and the corresponding readings were recorded. Tensile load, tensile stress and tensile modulus graphs were retrieved from the machine after the experiment. Figure 5 (a) shows the tensile load-extension graph. Figure 5 (b) shows the tensile stress-strain curves for 3 different

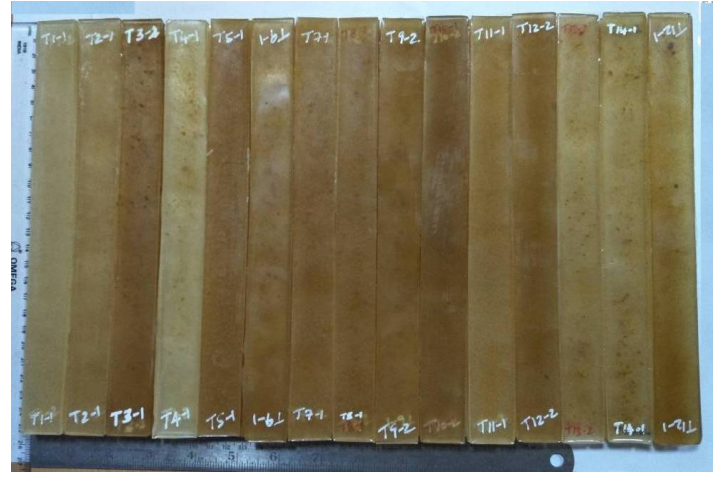

Figure 4: Tensile samples prepared according to ASTM D3039/D3039-15

$\mathrm{NaOH}$ treated $\mathrm{CMF}$ reinforced epoxy composite samples. The curve of run no. 2 represents the

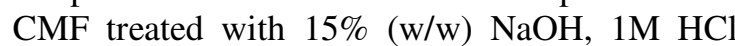
and $2 \%(\mathrm{w} / \mathrm{w}) \mathrm{NaOH}$ solutions. The curve of run no. 8 represents the CMF treated with $17.5 \%$ (w/w) $\mathrm{NaOH}, 1 \mathrm{M} \mathrm{HCl}$ and $2 \%(w / w) \mathrm{NaOH}$ solutions. Finally, the curve of run no. 4 represents the CMF treated with $20 \%(\mathrm{w} / \mathrm{w})$ $\mathrm{NaOH}, 1 \mathrm{M} \mathrm{HCl}$ and $2 \%(\mathrm{w} / \mathrm{w}) \mathrm{NaOH}$ solutions. From the graph, it is clear that the $20 \%$ (w/w) $\mathrm{NaOH}$ treated CMFs performed better than the other two. It seems that an increase in the $\mathrm{NaOH}$ concentration increases the surface area of the 


\section{VIGNESH PRAGASAM and DEGALAHAL MALLIKARJUNA REDDY}

fiber, by solubilizing more lignin and pectin in the successive chemical treatments. The increase in the surface area enhances the bonding between the CMFs and the resin, thus, the mechanical strength of the composite is increased. Figure 6 shows the main effects plots for tensile stress (a) and tensile modulus (b) of the composites. It may be noted that the increase in the pretreatment $\mathrm{NaOH} \%$ increases the tensile stress, while it initially increases and then decreases the tensile modulus. As regards the other two parameters, i.e. fiber size and fiber volume, the graph shows the same trend for both tensile stress and modulus.

Table 3 shows the values of tensile stress and tensile modulus for all the samples, with mean and standard deviation values. Standard deviation values show that there is very little variation among the trials and hence the results are consistent for all the samples. Table 4 shows experimental and predicted values of tensile stress and tensile modulus for 15 samples, obtained from the INSTRON machine and Design Expert software, respectively. The tensile stress and tensile modulus values of the pure epoxy sample are also included for the sake of comparison. From Table 4, it is evident that the epoxy reinforced with $20 \% \mathrm{NaOH}$ treated filler (run no. 14) shows higher tensile stress and modulus, compared to the other samples.

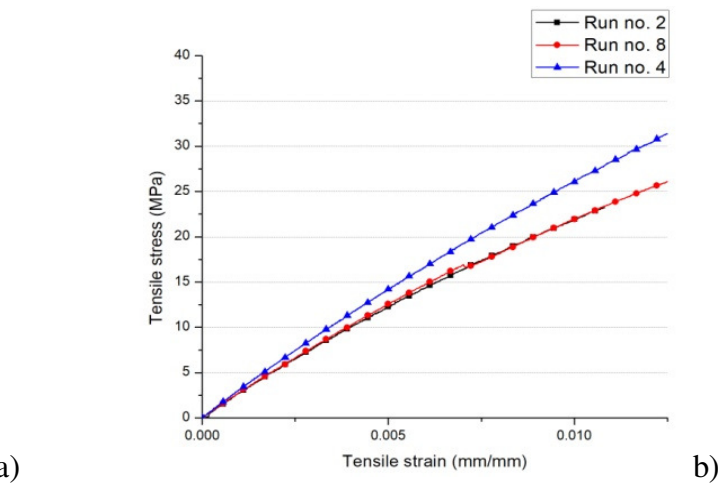

a)

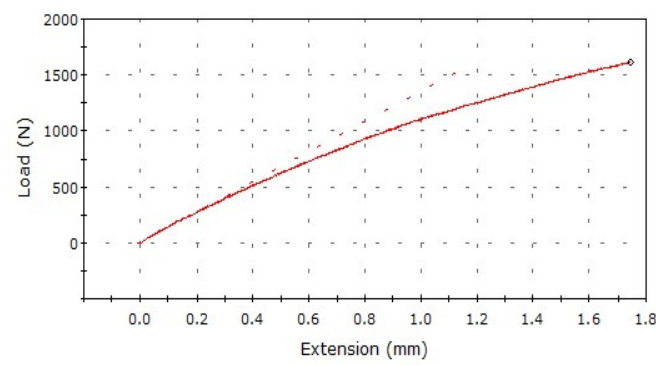

Figure 5: Sample tensile load-extension graph obtained from INSTRON (a), tensile stress-strain graph for samples containing differently treated fibers (b)

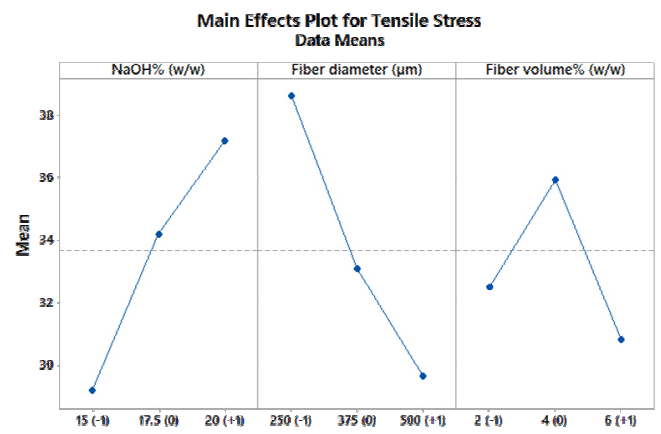

a)

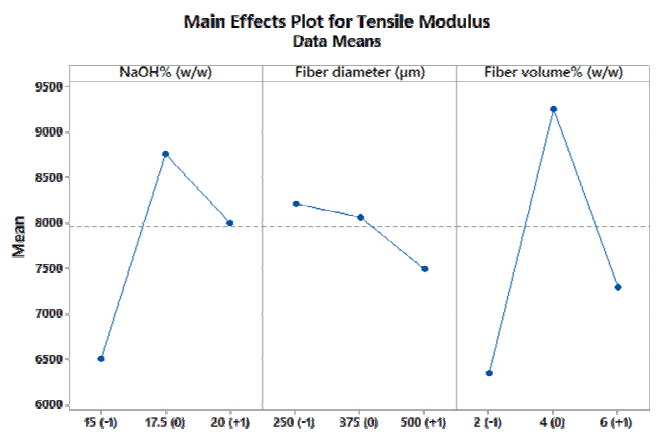

Figure 6: Main effects plots for tensile stress (a) and tensile modulus (b)

\section{Model fitting and ANOVA}

The main effects of $\mathrm{NaOH} \%$ (w/w), fiber diameter and fiber volume can be analyzed using the regression equations. Equations 2 and 3 show the quadratic polynomial regression equations for tensile stress and tensile modulus, respectively: where $\mathrm{A}-\mathrm{NaOH} \%(\mathrm{w} / \mathrm{w}), \mathrm{B}$ - fiber diameter $(\mu \mathrm{m}), \mathrm{C}-$ fiber vol\% (w/w). From Equation 2, it is clear that fiber vol\% (w/w) plays an important role in tensile stress, while Equation 3 indicates that $\mathrm{NaOH} \%(\mathrm{w} / \mathrm{w})$ plays an important role in tensile modulus. An increase in fiber vol\% (w/w) and $\mathrm{NaOH} \%$ (w/w) will raise the tensile stress and tensile modulus, respectively. 
Table 3

Complete tensile stress and tensile modulus results with mean and standard deviation

\begin{tabular}{|c|c|c|c|c|c|c|c|c|c|c|}
\hline \multirow[b]{2}{*}{$\begin{array}{c}\text { Run } \\
\text { no. }\end{array}$} & \multicolumn{5}{|c|}{ Tensile stress (MPa) } & \multicolumn{5}{|c|}{ Tensile modulus (MPa) } \\
\hline & Trail 1 & Trail 2 & Trail 3 & Mean & $\begin{array}{l}\text { Standard } \\
\text { deviation }\end{array}$ & Trail 1 & Trail 2 & Trail 3 & Mean & $\begin{array}{l}\text { Standard } \\
\text { deviation }\end{array}$ \\
\hline 1 & 28.628 & 40.416 & 31.996 & 33.68 & 6.072 & 5821.395 & 8218.440 & 6506.265 & 6848.70 & 1232.667 \\
\hline 2 & 24.553 & 30.038 & 23.769 & 26.12 & 3.416 & 4934.314 & 6036.661 & 4776.836 & 5249.27 & 686.4311 \\
\hline 3 & 30.821 & 43.512 & 34.447 & 36.26 & 6.537 & 9053.426 & 13159.050 & 9369.244 & 10527.24 & 2284.678 \\
\hline 4 & 31.102 & 43.908 & 35.761 & 36.59 & 6.596 & 6949.779 & 9811.452 & 7767.400 & 8176.21 & 1473.987 \\
\hline 5 & 33.652 & 41.170 & 32.578 & 35.80 & 4.681 & 7679.631 & 9395.293 & 7434.536 & 8169.82 & 1068.343 \\
\hline 6 & 21.861 & 31.775 & 22.624 & 25.42 & 5.517 & 5366.073 & 7799.525 & 5553.262 & 6239.62 & 1354.156 \\
\hline 7 & 24.404 & 34.452 & 27.275 & 28.71 & 5.176 & 7233.968 & 10212.660 & 8085.023 & 8510.55 & 1534.261 \\
\hline 8 & 30.821 & 43.512 & 34.447 & 36.26 & 6.537 & 9895.606 & 12106.326 & 9579.788 & 10527.24 & 1376.615 \\
\hline 9 & 35.071 & 50.975 & 36.294 & 40.78 & 8.850 & 5691.532 & 8272.575 & 5890.073 & 6618.06 & 1436.287 \\
\hline 10 & 30.218 & 42.660 & 33.773 & 35.55 & 6.409 & 7064.393 & 9973.260 & 7895.498 & 8311.05 & 1498.296 \\
\hline 11 & 23.848 & 29.176 & 23.087 & 25.37 & 3.318 & 5175.555 & 6331.797 & 5010.378 & 5505.91 & 719.9912 \\
\hline 12 & 32.413 & 47.113 & 33.544 & 37.69 & 8.180 & 6229.092 & 9053.913 & 6446.386 & 7243.13 & 1571.943 \\
\hline 13 & 30.821 & 43.512 & 34.447 & 36.26 & 6.537 & 9053.426 & 13159.050 & 9369.244 & 10527.24 & 1897.825 \\
\hline 14 & 38.991 & 47.702 & 37.747 & 41.48 & 5.424 & 9150.139 & 11194.319 & 8858.113 & 9734.19 & 1272.911 \\
\hline 15 & 24.673 & 35.863 & 25.534 & 28.69 & 6.226 & 6066.741 & 8817.938 & 6278.372 & 7054.35 & 1530.973 \\
\hline
\end{tabular}

Table 4

Experimental and predicted values of tensile stress and tensile modulus of composites and of pure epoxy

\begin{tabular}{ccccccccc}
\hline \multirow{2}{*}{$\begin{array}{c}\text { Run } \\
\text { no. }\end{array}$} & \multicolumn{3}{c}{ Tensile stress (MPa) } & \multicolumn{4}{c}{ Tensile modulus (MPa) } \\
\cline { 2 - 8 } & Experimental & Predicted & $\begin{array}{c}\text { Residual } \\
\text { error }\end{array}$ & \%Error & Experimental & Predicted & $\begin{array}{c}\text { Residual } \\
\text { error }\end{array}$ & \%Error \\
\hline 1 & 33.68 & 34.81 & -1.130 & -3.35 & 6848.70 & 7168.77 & -320.07 & -4.67 \\
2 & 26.12 & 28.77 & -2.650 & -10.14 & 5249.27 & 4709.72 & 539.55 & 10.27 \\
3 & 36.26 & 35.98 & 0.276 & 0.76 & 10527.24 & 10309.23 & 218.01 & 2.07 \\
4 & 36.59 & 36.60 & -0.007 & 0.02 & 8176.21 & 7804.89 & 371.32 & 4.54 \\
5 & 35.80 & 35.37 & 0.428 & 1.12 & 8169.82 & 9307.41 & -1137.59 & -13.92 \\
6 & 25.42 & 25.77 & -0.355 & -1.39 & 6239.62 & 7214.06 & -974.44 & -15.62 \\
7 & 28.71 & 28.61 & 0.100 & 0.35 & 8510.55 & 8170.59 & 339.96 & 4.03 \\
8 & 36.26 & 35.98 & 0.275 & 0.76 & 10527.24 & 10309.23 & 218.01 & 2.07 \\
9 & 40.78 & 39.73 & 2.052 & 5.03 & 6618.06 & 7214.06 & -596.00 & -9.21 \\
10 & 35.55 & 33.04 & 2.514 & 7.06 & 8311.05 & 8170.59 & 140.46 & 1.69 \\
11 & 25.37 & 26.84 & -1.473 & -5.75 & 5505.91 & 5666.25 & -160.34 & -2.92 \\
12 & 37.69 & 36.74 & 0.953 & 2.53 & 7243.13 & 6212.24 & 1030.89 & 14.23 \\
13 & 36.26 & 35.98 & 0.276 & 0.76 & 10527.24 & 10309.23 & 218.01 & 2.07 \\
14 & 41.48 & 44.57 & -3.092 & -7.45 & 9734.19 & 9307.41 & 426.78 & 4.38 \\
15 & 28.69 & 27.40 & 1.293 & 4.53 & 7054.35 & 7804.89 & -750.54 & -10.64 \\
16 & & & ---- & & & 4337.98 & & -- \\
\hline
\end{tabular}

Table 5 shows the ANOVA for the tensile stress quadratic model. The model p-value is $<0.0001$, which shows the significance of the model. The p-values of other factors, such as A, $B, B C, C^{2}$, reached $<0.05$. The predicted $R^{2}$ value is 0.9224 , which is very close to the adjusted $R^{2}$ value of 0.8871 . The difference between the predicted $R^{2}$ value and the adjusted $R^{2}$ value is less than 0.2 , and hence the model is significant.

Table 6 shows the ANOVA for the tensile modulus quadratic model. The model $\mathrm{p}$-value is $<0.0001$, which shows the significance of the model. The p-values of other factors, such as A,
$\mathrm{A}^{2}, \mathrm{C}^{2}$, reached $<0.05$. The predicted $\mathrm{R}^{2}$ value is 0.9045 , which is close to the adjusted $R^{2}$ value of 0.8726 . The difference between the predicted $\mathrm{R}^{2}$ value and the adjusted $R^{2}$ value is also less than 0.2 , and hence the model is significant.

Figure 7 (a) presents the predicted vs. actual values of tensile stress. The points in the graph are close to the line and grouped, which indicates that the predicted and actual values are close to each other. Figure 7 (b) shows the predicted vs. actual values of tensile modulus. The points in the graph are a bit scattered. The variation between 


\section{VIGNESH PRAGASAM and DEGALAHAL MALLIKARJUNA REDDY}

the predicted values and the actual ones is a bit wider, but the points are still within the range.

\section{Effects of parameters}

In BBD, three factors at three levels were utilized to study the influence of $\mathrm{NaOH}$, fiber size and fiber volume on the tensile stress and tensile modulus of chemically treated cellulose microfibril reinforced epoxy composites. The 3D response surface plots were developed to show the main and the interactive effects of the independent and the response variables. These graphs are easy to understand and very useful to intercept the numerical values graphically. The graphs are generated between two independent variables, keeping one variable constant for better understanding the effects of the variables and also to find the optimum conditions. Figure 8 (a) shows the response surface plot effect of fiber diameter and fiber volume on the tensile stress by keeping the percentage of $\mathrm{NaOH}$ constant at $17.5 \% \mathrm{w} / \mathrm{w}$. According to the graph, the maximum tensile stress is reached at a fiber diameter of 250 microns and a fiber volume of $4 \% \mathrm{w} / \mathrm{w}$ ratio.

Figure 8 (b) shows the response surface plot effect of $\mathrm{NaOH}$ and fiber diameter on the tensile modulus, while keeping the fiber volume at a $4 \%$ w/w ratio. According to Figure 8 (b), the maximum tensile modulus is attained at $18.5 \%$ w/w of $\mathrm{NaOH}$. The fiber diameter does not have any influence on the tensile modulus, whereas the fiber volume should be at a $4 \% \mathrm{w} / \mathrm{w}$ ratio. The surface plot effects indicate that a higher $\mathrm{NaOH}$ percentage increases the surface area of natural fiber.

Table 5

ANOVA results of the quadratic regression model for tensile stress

\begin{tabular}{lcccccc}
\hline Source & Sum of squares & df & Mean square & F-value & p-value & Remarks \\
\hline Model & 400.72 & 5 & 80.14 & 26.13 & $<0.0001$ & significant \\
A-NaOH & 127.04 & 1 & 127.04 & 41.43 & $<0.0001$ & \\
B-Fiber diameter & 169.10 & 1 & 169.10 & 55.14 & $<0.0001$ & \\
C-Fiber volume & 7.41 & 1 & 7.41 & 2.42 & 0.1483 & \\
$\mathrm{BC}$ & 22.66 & 1 & 22.66 & 7.39 & 0.0200 & \\
$\mathrm{C}^{2}$ & 74.51 & 1 & 74.51 & 24.30 & 0.0005 & \\
Residual & 33.73 & 11 & 3.07 & & & \\
Lack of fit & 33.73 & 7 & 4.82 & & \\
Pure error & 0.0000 & 4 & 0.0000 & & & \\
Cor. total & 434.45 & 16 & & & & \\
$\mathrm{R}^{2}$ & 0.9224 & & & & & \\
Adjusted $\mathrm{R}^{2}$ & 0.8871 & & & & & \\
Predicted $\mathrm{R}^{2}$ & 0.6941 & & & & & \\
\hline
\end{tabular}

Table 6

ANOVA results of the quadratic regression model for tensile modulus

\begin{tabular}{lcccccc}
\hline Source & Sum of squares & df & Mean square & F-value & p-value & Remarks \\
\hline Model & $5.052 \mathrm{E}+07$ & 4 & $1.263 \mathrm{E}+07$ & 28.40 & $<0.0001$ & significant \\
A-NaOH & $4.515 \mathrm{E}+06$ & 1 & $4.515 \mathrm{E}+06$ & 10.15 & 0.0078 & \\
C-Fiber volume & $1.830 \mathrm{E}+06$ & 1 & $1.830 \mathrm{E}+06$ & 4.11 & 0.0653 & \\
$\mathrm{~A}^{2}$ & $1.298 \mathrm{E}+07$ & 1 & $1.298 \mathrm{E}+07$ & 29.18 & 0.0002 & \\
$\mathrm{C}^{2}$ & $2.891 \mathrm{E}+07$ & 1 & $2.891 \mathrm{E}+07$ & 65.01 & $<0.0001$ & \\
Residual & $5.337 \mathrm{E}+06$ & 12 & $4.448 \mathrm{E}+05$ & & & \\
Lack of fit & $5.337 \mathrm{E}+06$ & 8 & $6.671 \mathrm{E}+05$ & & \\
Pure error & 0.0000 & 4 & 0.0000 & & & \\
Cor. total & $5.586 \mathrm{E}+07$ & 16 & & & & \\
$\mathrm{R}^{2}$ & 0.9045 & & & & & \\
Adjusted $\mathrm{R}^{2}$ & 0.8726 & & & & & \\
Predicted R & 0.7754 & & & & & \\
\hline
\end{tabular}




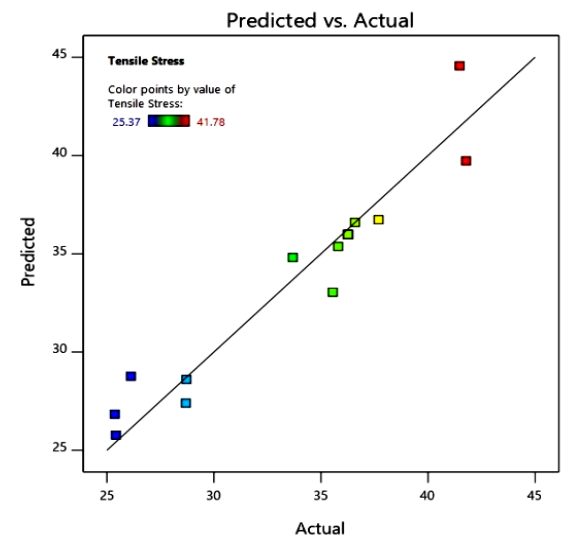

a)

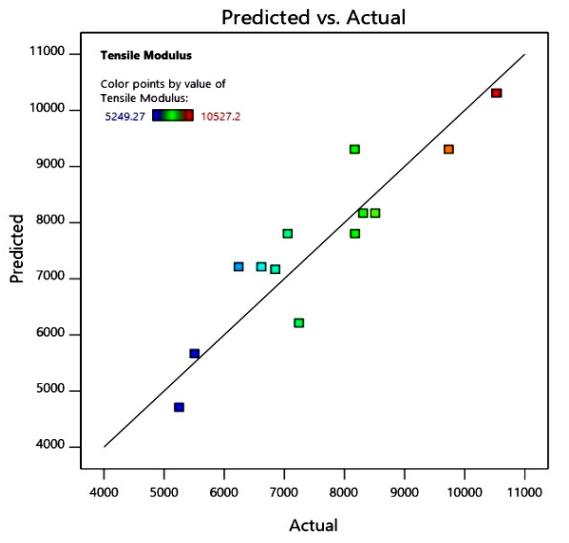

Figure 7: Graphs of predicted vs. actual values for tensile stress (a) and tensile modulus (b)

b)

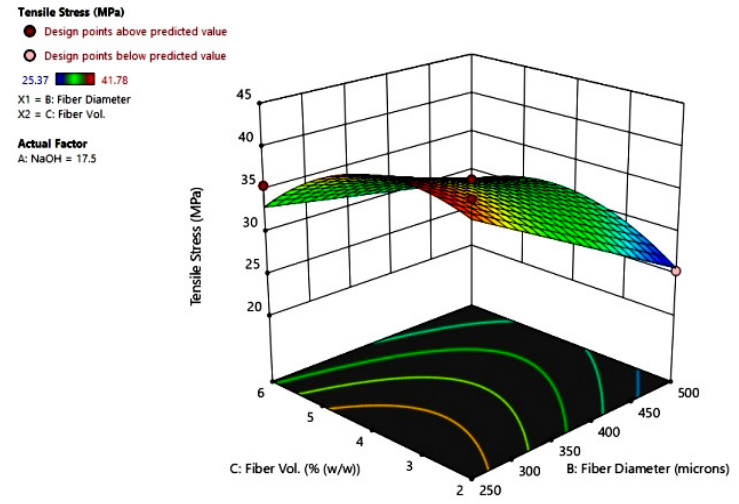

a)

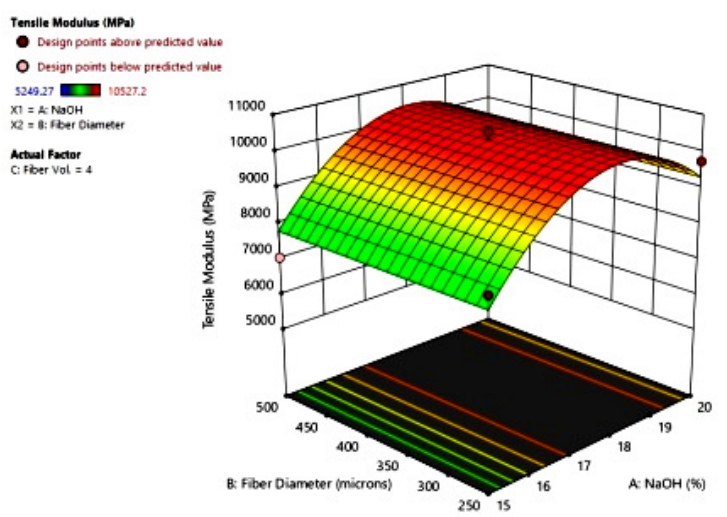

b)

Figure 8: Response surface plots showing (a) the effects of fiber diameter and fiber volume, as well as their interactive effect, on tensile stress for $17.5 \%(\mathrm{w} / \mathrm{w}) \mathrm{NaOH}$, and (b) the effects of $\mathrm{NaOH}$ and fiber diameter, as well as their interactive effect, on tensile modulus for $4 \%(\mathrm{w} / \mathrm{w})$ fiber volume
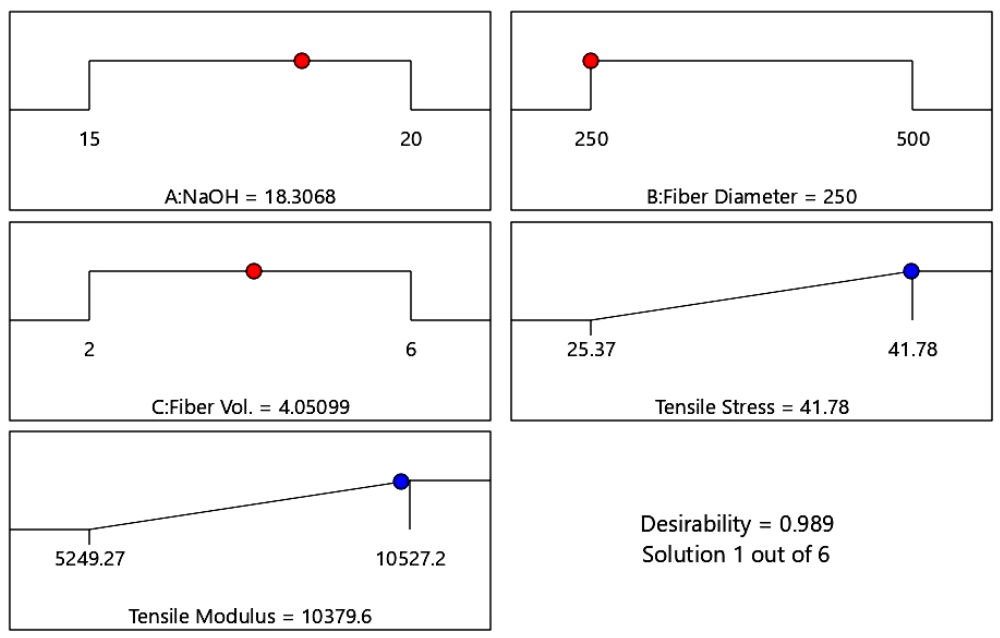

Desirability $=0.989$

Solution 1 out of 6

Figure 9: Desirability ramp for optimization

This increase in the surface area aids the matrix to penetrate well and create very good bonding with the natural fiber. Further, chemical treatment increases the chance of exposing more cellulose fibrils to the matrix material, which, in turn, increases the mechanical strength of the cellulose fibril reinforced composites. 


\section{Optimization and verification of the model}

Derringer's desirability function was employed as optimization methodology to find the optimum conditions to achieve maximum tensile stress and modulus values. ${ }^{49}$ 'Maximum level' and 'high importance' data for tensile stress were fed into the software, which provided the optimized conditions. Figure 9 shows the desirability ramp for optimizing the input variables to obtain the maximum outcome. According to Figure 9, it is recommended to set the input variables of $\mathrm{NaOH}$ to $18.31 \% \mathrm{w} / \mathrm{w}$ ratio, fiber diameter to $250 \mu \mathrm{m}$ and fiber volume to $4.05 \% \mathrm{w} / \mathrm{w}$ ratio in order to obtain the maximum outcome for tensile stress of $41.78 \mathrm{MPa}$ and tensile modulus of $10380 \mathrm{MPa}$. Table 7 shows six combinations of solutions with the desirability factor. From Table 7, the desirability of the ramp with 0.989 was selected as the optimized combination out of the six combinations proposed.

Table 7

Final settings for the optimal parameters derived by the software

\begin{tabular}{cccccccc}
\hline Number & $\mathrm{NaOH}$ & $\begin{array}{c}\text { Fiber } \\
\text { diameter }\end{array}$ & $\begin{array}{c}\text { Fiber } \\
\text { volume }\end{array}$ & $\begin{array}{c}\text { Tensile } \\
\text { stress }\end{array}$ & $\begin{array}{c}\text { Tensile } \\
\text { modulus }\end{array}$ & Desirability & Remarks \\
\hline 1 & 18.309 & 250.001 & 4.053 & 41.780 & 10379.589 & 0.989 & Selected \\
\hline 2 & 18.329 & 250.001 & 4.070 & 41.780 & 10379.225 & 0.989 & \\
3 & 18.288 & 250.005 & 4.034 & 41.780 & 10379.194 & 0.989 & \\
4 & 18.348 & 250.000 & 4.087 & 41.781 & 10378.163 & 0.989 & \\
5 & 18.383 & 250.649 & 4.105 & 41.780 & 10373.683 & 0.989 & \\
6 & 18.426 & 250.001 & 4.090 & 41.900 & 10363.111 & 0.988 & \\
\hline
\end{tabular}

\section{CONCLUSION}

In the present study, the Box-Behnken Design method was employed to obtain optimized process parameters. The three-parameter, threelevel model was used and the variables considered for this study were $\mathrm{NaOH} \%$ (w/w), fiber diameter $(\mu \mathrm{m})$ and fiber volume\% (w/w). Triplicate specimens were prepared and tested using the INSTRON 8801 machine. Tensile stress and tensile modulus results were tabulated, analyzed and optimized using Design-Expert software. The experimental values and predicted values were found to be in good agreement, with high $\mathrm{R}^{2}$ values of $92.2 \%$ for tensile stress and of $90.4 \%$ for tensile modulus obtained by ANOVA. The effect of the variables on tensile stress and tensile modulus was clearly explained with the help of $3 \mathrm{D}$ response surface graphs. The optimum tensile stress and tensile moduli were $41.78 \mathrm{MPa}$ and $10380 \mathrm{MPa}$, respectively, using the optimized values of $\mathrm{NaOH} \%(\mathrm{w} / \mathrm{w})$, fiber diameter $(\mu \mathrm{m})$ and fiber volume $\%(\mathrm{w} / \mathrm{w})$ of $18.31,250$ and 4.05, respectively. The desirability ramp values and the combination solution tables were also presented. This study proves that the Box-Behnken Design can be successfully applied to model cellulose microfibril reinforced polymer composites, providing optimized results within a short period of time and with a minimal number of experimental runs.
ACKNOWLEDGMENT: The authors are very grateful to the Vellore Institute of Technology, Vellore Campus, India. This work was financially supported by the Institution of Engineers (India) IEI [DR2019005].

\section{REFERENCES}

1 V. Suthenthiraveerappa and V. Gopalan, J. Reinf. Plast. Comp., 36, $1453 \quad$ (2017), https://doi.org/10.1177/0731684417710108

2 A. Alemdar and M. Sain, Bioresour. Technol., 99, 1664

https://doi.org/10.1016/j.biortech.2007.04.029

(2008),

3 A. Alemdar and M. Sain, Compos. Sci. Technol., 68, 557

(2008),

https://doi.org/10.1016/j.compscitech.2007.05.044

4 A. M. Edeerozey, H. M. Akil, A. B. Azhar and M. Z. Ariffin, Mater. Lett., 61, 2023 (2007), https://doi.org/10.1016/j.matlet.2006.08.006

5 D. Feng, D. F. Caulfield and A. R. Sanadi, Polym. Compos., $\quad 22, \quad 506 \quad$ (2001), https://doi.org/10.1002/pc.10555

S. Kalia, B. S. Kaith and I. Kaur, Polym. Eng. Sci., 49, 1253 (2009), https://doi.org/10.1002/pen.21328

7 M. Rokbi, H. Osmani, A. Imad and N. Benseddiq, Procedia Eng., 10, $2092 \quad$ (2011), https://doi.org/10.1016/j.proeng.2011.04.346

8 M. M. Kabir, H. Wang, K. T. Lau and F. Cardona, Compos. Part B-Eng., 43, 2883 (2012), https://doi.org/10.1016/j.compositesb.2012.04.053

9 P. V. Joseph, K. Joseph, S. Thomas, C. K. S. Pillai, V. S. Prasad et al., Compos. Part A-Appl. Sci., 34, 253 
(2003), 835X(02)00185-9

10 Y. Zhou, M. Fan and L. Chen, Compos. Part BEng., 101, 31 (2016) https://doi.org/10.1016/j.compositesb.2016.06.055

11 R. Sepe, F. Bollino, L. Boccarusso and F. Caputo, Compos. Part B-Eng., 133, $210 \quad$ (2018), https://doi.org/10.1016/j.compositesb.2017.09.030

12 H. M. M. A. Rashed, M. A. Islam and F. B. Rizvi, J. Nav. Arch. Marine, 3, 1 (2006), https://doi.org/10.3329/jname.v3i1.923

13 M. Boopalan, M. Niranjanaa and M. J. Umapathy, Compos. Part B-Eng., 51, $54 \quad$ (2013), https://doi.org/10.1016/j.compositesb.2013.02.033

14 S. Ochi, Mech. Mater., 40, 446 (2008), https://doi.org/10.1016/j.mechmat.2007.10.006

15 Z. N. Azwa and B. F. Yousif, Polym. Degrad., 98, 2752

(2013),

https://doi.org/10.1016/j.polymdegradstab.2013.10.008

16 R. Malkapuram, V. Kumar and Y. S. Negi, J. Reinf.

Plast. Comp., 28, $1169 \quad$ (2009), https://doi.org/10.1177/0731684407087759

17 S. A. Paul, A. Boudenne, L. Ibos, Y. Candau, K. Joseph et al., Compos. Part A-Appl. Sci., 39, 1582 (2008),

https://doi.org/10.1016/j.compositesa.2008.06.004

18 S. Harish, D. P. Michael, A. Bensely, D. M. Lal and A. Rajadurai, Mater. Charact., 60, 44 (2009), https://doi.org/10.1016/j.matchar.2008.07.001

19 M. M. Haque, M. Hasan, M. S. Islam and M. E. Ali, Bioresour. Technol., 100, 4903 (2009), https://doi.org/10.1016/j.biortech.2009.04.072

20 B. H. Lee, H. J. Kim and W. R. Yu, Fiber Polym., 10, 83 (2009), https://doi.org/10.1007/s12221-0090083-z

21 H. L. Ornaghi Jr., H. S. P. da Silva, A. J. Zattera and S. C. Amico, Mater. Sci. Eng. A, 528, 7285 (2011), https://doi.org/10.1016/j.msea.2011.05.078

22 H. Akil, M. F. Omar, A. A. M. Mazuki, S. Z. A. M. Safiee, Z. M. Ishak et al., Mater. Des., 32, 4107 (2011), https://doi.org/10.1016/j.matdes.2011.04.008

23 A. R. Prasad and K. M. Rao, Mater. Des., 32, 4658 (2011), https://doi.org/10.1016/j.matdes.2011.03.015

24 T. P. Sathishkumar, P. Navaneethakrishnan and O. Shankar, Compos. Sci. Technol., 72, 1183 (2012), https://doi.org/10.1016/j.compscitech.2012.04.001

25 N. Venkateshwaran, A. Elayaperumal and G. K. Sathiya, Compos. Part B-Eng., 43, 793 (2012), https://doi.org/10.1016/j.compositesb.2011.08.023

26 M. Ramesh, K. Palanikumar and K. H. Reddy, Compos. Part B-Eng., 48, 1 (2013), https://doi.org/10.1016/j.compositesb.2012.12.004

27 M. Jawaid, H. A. Khalil, A. Hassan, R. Dungani and A. Hadiyane, Compos. Part B-Eng., 45, 619 (2013), https://doi.org/10.1016/j.compositesb.2012.04.068 28 M. R. Sanjay, G. R. Arpitha, L. L. Naik, K. Gopalakrishna and B. Yogesha, J. Mater. Environ. $\begin{array}{llll}\text { Sci., } & \text { 7, } & 3179 & \text { (2016), }\end{array}$
https://www.jmaterenvironsci.com/Document/vol7/vol 7_N9/332-JMES-2102-Sanjay.pdf

${ }^{29}$ R. Gunti, A. V. Ratna Prasad and A. V. S. S. K. S. Gupta, Polym. Compos., 39, $1125 \quad$ (2018), https://doi.org/10.1002/pc.24041

30 Y. Wu, C. Xia, L. Cai, A. C. Garcia and S. Q. Shi, J. Clean. Prod., 184, $92 \quad$ (2018), https://doi.org/10.1016/j.jclepro.2018.02.257

31 C. Baley, M. Lan, A. Bourmaud and A. Le Duigou, Mater. Today Commun., 16, 300 (2018), https://doi.org/10.1016/j.mtcomm.2018.07.003

32 M. R. Sanjay, P. Madhu, M. Jawaid, P. Senthamaraikannan, S. Senthil et al., J. Clean. Prod., 172, $566 \quad$ (2018), https://doi.org/10.1016/j.jclepro.2017.10.101

${ }_{33}$ M. H. Alaaeddin, S. M. Sapuan, M. Y. M. Zuhri, E. S. Zainudin and F. M. Al-Oqla, J. Clean. Prod., 235, 473

(2019), https://doi.org/10.1016/j.jclepro.2019.06.341

34 R. Jumaidin, S. M. Sapuan, M. Jawaid, M. R. Ishak and J. Sahari, Int. J. Biol. Macromol., 89, 575 (2016), https://doi.org/10.1016/j.ijbiomac.2016.05.028

35 G. Navaneethakrishnan, T. Karthikeyan, S. Saravanan, V. Selvam, N. Parkunam et al., Mater. $\begin{array}{llll}\text { Today Proc., } & \text { 21, } & 7 & \text { (2020), }\end{array}$ https://doi.org/10.1016/j.matpr.2019.05.295

36 D. K. K. Cavalcanti, M. D. Banea, J. S. S. Neto, R. A. A. Lima, L. F. M. da Silva et al., Compos. Part BEng., 175, 107149 (2019), https://doi.org/10.1016/j.compositesb.2019.107149

37 A. G. Adeniyi, D. V. Onifade, J. O. Ighalo and A. S. Adeoye, Compos. Part B-Eng., 176, 107305 (2019), https://doi.org/10.1016/j.compositesb.2019.107305

${ }_{38}$ K. Senthilkumar, N. Saba, M. Chandrasekar, M. Jawaid, N. Rajini et al., Const. Build. Mater., 195, 423 (2019), https://doi.org/10.1016/j.conbuildmat.2018.11.081

39 S. S. Laxmeshwar, D. J. Madhu Kumar, S. Viveka and G. K. Nagaraja, ISRN Polym. Sci., 2012, 1 (2012), https://doi.org/10.5402/2012/154314

${ }^{40}$ L. Wu, K. L. Yick, S. P. Ng and J. Yip, Expert Syst. Appl., $\quad 39, \quad 8059 \quad$ (2012), https://doi.org/10.1016/j.eswa.2012.01.137

${ }^{41}$ B. Y. Tak, B. S. Tak, Y. J. Kim, Y. J. Park, Y. H. Yoon et al., J. Ind. Eng. Chem., 28, 307 (2015), https://doi.org/10.1016/j.jiec.2015.03.008

${ }^{42}$ N. Aslan and Y. Cebeci, Fuel, 86, 90 (2007), https://doi.org/10.1016/j.fuel.2006.06.010

43 A. Soundhar, M. Rajesh, K. Jayakrishna, M. T. H. Sultan and A. U. M. Shah, Nanocomposites, 5, 1 (2019), https://doi.org/10.1080/20550324.2018.1562614

44 ASTM Standard D3039/D3039M, 2017, "Standard Test Method for Tensile Properties of Polymer Matrix Composite Materials," ASTM International, West Conshohocken, PA, 2017, https://doi.org/10.1520/D3039M-17 


\section{VIGNESH PRAGASAM and DEGALAHAL MALLIKARJUNA REDDY}

45 M. M. Ibrahim, A. Dufresne, W. K. El-Zawawy and F. A. Agblevor, Carbohyd. Polym., 81, 811 (2010), https://doi.org/10.1016/j.carbpol.2010.03.057

46 J. J. Kenned, K. Sankaranarayanasamy, J. S. Binoj and S. K. Chelliah, Comp. Sci. Technol., 185, 107890 (2020), https://doi.org/10.1016/j.compscitech.2019.107890

47 P. Anand and V. Anbumalar, Cellulose Chem. Technol.,
91

(2017),
http://www.cellulosechemtechnol.ro/pdf/CCT12(2017)/p.91-101.pdf

48 J. Girones, T. T. L. Vo, E. Di Giuseppe and P. Navard, Cellulose Chem. Technol., 51, 839 (2017), http://www.cellulosechemtechnol.ro/pdf/CCT910(2017)/p.839-855.pdf

49 J. P. Maran, S. Manikandan, K. Thirugnanasambandham, C. V. Nivetha and R. Dinesh, Carbohyd. Polym., 92, $604 \quad$ (2013), https://doi.org/10.1016/j.carbpol.2012.09.020 